\title{
Improved production of succinic acid from Basfia succiniciproducens growing on $A$. donax and process evaluation through material flow analysis
}

Donatella Cimini ${ }^{* *} \mathbb{D}$, Lucio Zaccariello², Sergio D'Ambrosio ${ }^{1}$, Licia Lama ${ }^{3}$, Giovanna Ruoppolo ${ }^{4}$, Olimpia Pepe ${ }^{5}$, Vincenza Faraco ${ }^{6}$ and Chiara Schiraldi ${ }^{1}$

\begin{abstract}
Background: Due to its wide range of applications in the food, pharmaceutical and chemical fields, microbial synthesis of succinic acid is receiving growing attention, generating already relevant industrial results, as well as fueling constant research for improvements. In order to develop a sustainable process, a special focus is now set on the exploitation and conversion of lignocellulosic biomasses into platform chemicals.

Results: In the present work we used Basfia succiniciproducens BPP7 in separated hydrolysis and fermentation experiments with Arundo donax as starting material. Fed-batch strategies showed a maximal production of about $37 \mathrm{~g} / \mathrm{L}$ of succinic acid after $43 \mathrm{~h}$ of growth and a productivity of $0.9 \mathrm{~g} / \mathrm{L} \mathrm{h}$ on the pilot scale. Global mass balance calculations demonstrated a hydrolysis and fermentation efficiency of about 75\%. Moreover, the application of a material flow analysis showed the obtainment of 88.5 and $52 \%$ of succinic acid, per $\mathrm{kg}$ of virgin biomass and on the total generated output, respectively.

Conclusions: The use of fed-batch strategies for the growth of B. succiniciproducens on A. donax improved the titer and productivity of succinic acid on pre-pilot scale. Process evaluation through material flow analysis showed successful results and predicted a yield of succinic acid of about $30 \%$ in a fed-batch process that uses A. donax as only carbon source also in the feed. Preliminary considerations on the possibility to achieve an energetic valorization of the residual solid coming from the fermentation process were also carried out.
\end{abstract}

Keywords: Basfia succiniciproducens, Arundo donax, Fed-batch, Succinic acid, Pre-pilot scale, Inhibition, Material flow analysis

\section{Introduction}

Due to its recent applications as specialty chemical for the production of biopolymers, and bioplastics in particular, the establishment of sustainable processes for microbial production of succinic acid is receiving great attention [1]. Several biotech companies that appeared in the past few years (e.g. Myriant, Reverdia, BioAmber, and

\footnotetext{
*Correspondence: donatella.cimini@unicampania.it

${ }^{1}$ Department of Experimental Medicine, University of Campania L.

Vanvitelli, Via de Crecchio 7, 80138 Naples, Italy

Full list of author information is available at the end of the article
}

Succinity) established bio-based production platforms that mainly exploit recombinant microorganisms to convert purified sugars into this added value compound [2, 3]. However, as for bio-ethanol production, currently, the identification of strategies that allow conversion of nonfood waste materials into platform chemicals is of great value, and bio-based succinic acid production is regarded as one of the fastest growing markets [4]. Diverse lignocellulosic biomasses were used as raw materials for the development of small-scale fermentation processes with natural producers of succinic acid [5-7]; however, extraction of fermentable sugars from complex matrices

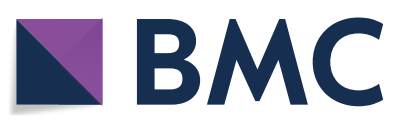

(c) The Author(s) 2019. This article is distributed under the terms of the Creative Commons Attribution 4.0 International License (http://creativecommons.org/licenses/by/4.0/), which permits unrestricted use, distribution, and reproduction in any medium, provided you give appropriate credit to the original author(s) and the source, provide a link to the Creative Commons license, and indicate if changes were made. The Creative Commons Public Domain Dedication waiver (http://creativecommons.org/ publicdomain/zero/1.0/) applies to the data made available in this article, unless otherwise stated. 
is often associated with low sugar yields and release of compounds that inhibit microbial growth during hydrolysis [8]. In this work, the dedicated energy crop, Arundo donax, was used as source for biological production of succinic acid from Basfia succiniciproducens BPP7 [9]. In fact, it was previously shown that this strain is able to grow on (50\%) diluted perennial cane in batch processes up to the pilot scale $(150 \mathrm{~L})$, also demonstrating the ability to detoxify some of the inhibitory molecules found in the hydrolysate such as hydroxymethylfurfural (HMF), furfural and vanillin $[10,11]$. Other examples in literature show the ability of B. succiniciproducens to produce succinic acid from various renewable materials. Recently a yield of $0.69 \mathrm{~g} / \mathrm{g}$ (on consumed sugar) and a productivity of $0.43 \mathrm{~g} / \mathrm{L} \mathrm{h}$ of succinic acid were obtained by growing B. succiniciproducens on corn stover in $0.5 \mathrm{~L}$ reactors [11]. Besides the potential additional costs for the design of support materials, and the need for process optimization, the production of $45 \mathrm{~g} / \mathrm{L}$ of succinic acid with a productivity of $0.58 \mathrm{~g} / \mathrm{L}$ h from nanofiltered spent sulphite liquor was achieved in $0.5 \mathrm{~L}$ fed-batch processes with immobilized cells [12].

In the present work fed-batch experiments in anaerobic conditions were conducted on pre-pilot scale bioreactors, growing this promising strain on $A$. donax hydrolysate. A different approach based on a material flow analysis (MFA) method was also established to evaluate the efficiency of the whole process. In particular, the experimental results obtained from the tests of hydrolysis and fermentation, together with those generated by MFA, were combined in order to evaluate the performance of the supposed succinic acid production process (SAPP) also considering the pre-treatment and purification step based on literature data. Moreover, the potential energetic valorization of the residue of the hydrolysis and fermentation processes was also evaluated by ultimate analysis.

\section{Materials and methods}

\section{Enzymatic hydrolysis of $A$. donax}

The lignocellulosic biomass, derived from dedicated crops of A. donax and steam pretreated according to Garbero and collaborators [13], was used for the production of fermentable monosaccharides, such as glucose and xylose, for subsequent fermentation experiments. After the treatment, the slurry was diluted in order to have a solid content of about $10 \% \mathrm{w} / \mathrm{v}\left(98 \mathrm{~g}_{\text {drybiomass }} / \mathrm{L}\right)$. The bioconversion process was carried out by slightly changing the previously described protocol [10] with the commercial enzymatic cocktail Novozymes NS22201. Briefly the mixture consisted of $1 \mathrm{~L}$ sodium acetate buffer at $\mathrm{pH}$ 5.2 per $\mathrm{kg}$ of wet lignocellulosic biomass and the final concentration of the applied sodium acetate buffer was
$50 \mathrm{mM}$ for an incubation period of $48 \mathrm{~h}$ at $45^{\circ} \mathrm{C} ; 140 \mathrm{U}$ of the enzymatic cocktail were added to $1 \mathrm{~g}$ of wet biomass and the units, expressed as units of cellulase activity, were determined utilizing the soluble chromogenic substrate carboxymethyl cellulose-Remazolbrillant Blue R (Azo-CM-cellulose, Megazyme, Ireland), calculated from a standard curve constructed with known amounts of cellulase from Tricoderma sp. After bioconversion, the liquid residue was removed with a peristaltic pump to separate them from the solids, which were used for the production of succinic acid. Before fermentation experiments the concentration of glucose and xylose released in the process, and present in the liquid fraction, was determined as described in "HPLC quantification of sugars, organic acids and inhibitors" section.

The conversion of cellulose and hemicellulose to glucose and xylose, respectively, as percentage of their theoretical yields from the saccharification of $A$. donax was calculated with the following equations according to [14]:

$$
\text { Cellulose conversion }(\%)=\frac{[\text { Glucose }]}{[\text { Biomass }] \cdot F_{\text {cell }} \cdot 1.11} \cdot 100
$$

$$
\text { Hemiellulose conversion }(\%)=\frac{[\text { Xylose }]}{[\text { Biomass }] \cdot F_{\text {hcell }} \cdot 1.14} \cdot 100 \text {, }
$$

where [Glucose or Xylose] is the concentrations of glucose and xylose found in the hydrolysates $(\mathrm{g} / \mathrm{L})$; [Biomass] is the concentration of dry $A$. donax used during the hydrolytic reaction $(\mathrm{g} / \mathrm{L}) ; F_{\text {cell }}$ and $F_{\text {hcell }}$ are the fractions of $\alpha$-cellulose and hemicelluloses in the dry biomass $(\mathrm{g} / \mathrm{g})$, respectively [15]; 1.11 and 1.14 are the factors for the conversion of glucans to glucose and xylans to xylose, respectively [16].

\section{Fermentation experiments}

Fermentation experiments were performed on a Biostat D (150 L total volume) with a working volume of 70-80 L (Sartorius Stedim; Melsungen, Germany). The seed culture was inoculated with the B. succiniciproducens BPP7 working cell bank and grown for $16 \pm 1 \mathrm{~h}$ in $0.25 \mathrm{~L}$ bottles on $\mathrm{MH}$ medium with glucose as $\mathrm{C}$-source and then transferred in a Biostat CT before performing the main cultivation in the Biostat D fermenter. All fermentations were carried out at $37{ }^{\circ} \mathrm{C}$ on $\mathrm{MH}$ medium containing the following per litre: $5 \mathrm{~g}$ yeast extract, $2 \mathrm{~g}\left(\mathrm{NH}_{4}\right)_{2} \mathrm{SO}_{4}, 0.2 \mathrm{~g}$ $\mathrm{CaCl}_{2} \cdot \mathrm{H}_{2} \mathrm{O}, 0.2 \mathrm{~g} \mathrm{MgCl}_{2} \cdot 6 \mathrm{H}_{2} \mathrm{O}, 2 \mathrm{~g} \mathrm{NaCl}, 3 \mathrm{~g} \mathrm{~K}_{2} \mathrm{HPO}_{4}$, $1 \mathrm{mg} \mathrm{Na} \mathrm{S}_{2} \cdot 9 \mathrm{H}_{2} \mathrm{O}$ supplemented with $50-60 \% A$. donax hydrolysate and run for up to $54 \mathrm{~h}$. The culture was sparged with $\mathrm{CO}_{2}$ at $0.1 \mathrm{vvm}$ and agitation speed was set to $100-200 \mathrm{rpm}$. A constant $\mathrm{pH}$ of 6.5 was maintained via automated addition of $25 \% \mathrm{v} / \mathrm{v} \mathrm{NH}_{4} \mathrm{OH}$ and $30 \% \mathrm{v} / \mathrm{v}$ $\mathrm{H}_{2} \mathrm{SO}_{4}$. For the fed-batch phase a concentrated feeding 
solution containing sugars and yeast extract was added to the broth to prolong growth. The feeding profiles provided addition of about $33-55 \mathrm{~g} / \mathrm{L}$ of total sugars either pure or diluted in $A$. donax with a rate ranging from 0.2 to $1.2 \mathrm{~g} / \mathrm{L} \mathrm{h}$. For the duration of all cultivations $50 \mathrm{~mL}$ samples were withdrawn from the reactors at regular time intervals for the determination of dry cell weight, substrate consumption and extracellular metabolite production.

The composition of $A$. donax hydrolysate used in the work is the following: glucose $28.9 \pm 2.9 \mathrm{~g} / \mathrm{L}$, xylose $15.6 \pm 1.4 \mathrm{~g} / \mathrm{L}$, acetic acid $5.6 \pm 0.6 \mathrm{~g} / \mathrm{L}$.

The global evaluation of process efficiency considering the conversion of cellulose and hemicellulose to monosaccharides and their fermentation to succinic acid was performed with the following equation: succinic acid before strain inoculation and cell growth was monitored by diluting the culture with $1 \mathrm{M} \mathrm{HCl}$, to remove $\mathrm{NaCO}_{3}$ /precipitates, and immediately establish cell concentration as optical density at $600 \mathrm{~nm}$. Every bottle experiment was repeated at least twice.

\section{HPLC quantification of sugars, organic acids and inhibitors} Broth samples were collected every $2 \mathrm{~h}$ during cultivations to follow biomass formation, substrate consumption and product formation. The supernatants obtained after centrifugation were ultrafiltered on $3 \mathrm{kDa}$ centricon devices (Millipore, Bedford, MA, USA) at $12000 \times g$ and the flow through was analysed for the determination of glucose, xylose and acids produced during growth by HPLC (UHPLC Dionex Ultimate

$$
\text { Eff. }(\%)=\frac{[\text { Succinic acid }] \cdot V_{\mathrm{s}}}{\left[\left([\mathrm{Cell}] \cdot V_{\mathrm{h}} \cdot 1.11\right)+\left([\text { Hcell }] \cdot V_{\mathrm{h}} \cdot 1.14\right)+\left([G] \cdot V_{\mathrm{s} .}\right)+\left([X] \cdot V_{\mathrm{s} .}\right)-\left(\left[G_{\mathrm{a}}\right] \cdot V_{\mathrm{s} .}\right)-\left([\mathrm{Xa}] \cdot V_{\mathrm{s} .}\right)\right] \cdot 1.12} \cdot 100 \text {, }
$$

where [Succinic acid] is the final concentration of succinic acid in the fermentation broth $(\mathrm{g} / \mathrm{L})$; [Cell or Hcell] is the concentration of $\alpha$-cellulose and hemicellulose in the dry biomass $(\mathrm{g} / \mathrm{L})$, respectively, as described by Shatalov and Pereira [15]; $V_{\mathrm{s}}$ is the volume of supernatant recovered after fermentation; $V_{\mathrm{h}}$ is the volume of hydrolysate added to the medium; $[G]$ and $[X]$ are the concentrations of pure glucose and xylose eventually supplemented during fermentation; $\left[G_{\mathrm{a}}\right]$ and $\left[X_{\mathrm{a}}\right]$ are the concentrations of accumulated glucose and xylose at the end of the FB; 1.12 is the conversion factor of glucose and xylose to succinic acid considering the maximum theoretical yield $[17,18] .1 .11$ and 1.14 are the factors for the conversion of glucans to glucose and xylans to xylose, respectively [16]. Conversion of hemicelluloses to glucose was negligible (about $0.6 \%$ ).

\section{Shake flasks experiments}

Growth inhibition experiments were conducted in $0.25 \mathrm{~L}$ bottles filled with $0.25 \mathrm{~L}$ of medium at $37{ }^{\circ} \mathrm{C}$ and $140 \mathrm{rpm}$, in a rotary shaker incubator (model Minitron, Infors, Bottmingen, Switzerland). Bottles were sealed with stainless steel headpiece caps and sterile venting filters to insufflate $\mathrm{CO}_{2}$, before starting the experiment and after 8, 24 and $36 \mathrm{~h}$ of growth. Experiments were conducted on standard $\mathrm{MH}$ medium containing the following per litre: $5 \mathrm{~g}$ yeast extract, $10 \mathrm{~g}$ soy peptone, $2 \mathrm{~g}\left(\mathrm{NH}_{4}\right)_{2} \mathrm{SO}_{4}, 0.2 \mathrm{~g} \mathrm{CaCl}_{2} \cdot \mathrm{H}_{2} \mathrm{O}, 0.2 \mathrm{~g} \mathrm{MgCl}_{2} \cdot 6 \mathrm{H}_{2} \mathrm{O}, 2 \mathrm{~g}$ $\mathrm{NaCl}, 3 \mathrm{~g} \mathrm{~K}_{2} \mathrm{HPO}_{4}, 10 \mathrm{~g} \mathrm{NaCO}_{3}, 1 \mathrm{mg} \mathrm{Na} \mathrm{S}_{2} \mathrm{H}_{2} \mathrm{O}$, supplemented with glucose as $\mathrm{C}$ source. The $\mathrm{MH}$ medium was supplemented with $10-20-30-40-50$ and $60 \mathrm{~g} / \mathrm{L}$
3000; Thermofisher) on a Alltech IOA-2000 column $(500 \mathrm{~mm} \times 6.5 \mathrm{~mm}$ ID). Analyses were performed at $40{ }^{\circ} \mathrm{C}$ with $0.1 \% \mathrm{v} / \mathrm{v}$ phosphoric acid in water as mobile phase at a flow rate of $0.6 \mathrm{~mL} / \mathrm{min}$. Detection was performed via UV absorbance at $200 \mathrm{~nm}$ and refraction index (Shodex RI-101 detector, Max auto step 5,1 s, Temperature $32{ }^{\circ} \mathrm{C}$, Rise time $1 \mathrm{~s}$, Polarity plus, Record Range $512 \mu$ RIU, Integrator Range $500 \mu$ RIU/UV).

\section{Determination of biomass composition}

The materials have been characterized to assess the possibility to obtain the energetic valorization of the residue of the hydrolysis and fermentation process. For this purpose the strain, the $A$. donax hydrolysate used as feedstock, and the residual solid obtained after fermentation, have been characterized by ultimate analysis, i.e. the determination of carbon, hydrogen and nitrogen content (oxygen was calculated by difference) using a CHN LECO CS144 analyser.

For these experiments, about $20 \mathrm{mg}$ of dried and homogenised sample (by grinding) was introduced in the apparatus. The $\mathrm{C}, \mathrm{H}, \mathrm{N}$ content was obtained by burning the sample at $950{ }^{\circ} \mathrm{C}$ and measuring the gaseous concentrations using a TCD for $\mathrm{N}_{2}$ (previously obtained from catalytic NOx reduction) and two separated NDIR cells for $\mathrm{C}$ and $\mathrm{H}$. For the ultimate analysis the protocol ASTM D 5373 has been used. The moisture, the volatile, the fixed carbon and the ash content of the all materials have been determined using a LECO TG701 thermo-gravimetric analyser using about $1.5 \mathrm{~g}$ of sample following the ASTM D5142 protocol. 


\section{Performance evaluation of an optimised succinic acid production facility}

In this section, by utilizing experimental results obtained from the hydrolysis and fermentation test FB4, which showed the best performance in term of succinic acid yield, a quantified process flow diagram for an optimised biochemical conversion of $A$. donax to succinic acid was defined. The optimised process (OP) provides the use of $A$. donax as the only carbon source, i.e. without the addition of pure glucose as shown during the fermentation test FB4.

The main operation units considered for the proposed OP are that of biomass pre-treatment, hydrolysis, fermentation and purification. The description of the additional units proposed to define the entire succinic acid production process, i.e. biomass pre-treatment and purification units, is as follows:

- The steam explosion process was considered as biomass pre-treatment method as it is a valuable technology to improve the recovery of sugars and other useful compounds from biomass [19];

- The downstream processing (purification unit) involves separation and purification steps that produce a purified succinic acid from the fermentation unit. In particular, it consists of a reactive extraction performed by using tri-n-octylamine in 1-octanol at $\mathrm{pH} 5$, a vacuum distillation and a crystallization process for the highly purified succinic acid production as reported by [20]. Before crystallization, $\mathrm{pH}$ was adjusted below 2 with $\mathrm{HCl}$ to convert succinate in succinic acid [20].

The experimental results, obtained from the tests of hydrolysis and fermentation (actual process, AP), literature data and those generated by a recently defined environmental assessment tool, the MFA, which is named substance flow analysis (SFA) when it is referred to a specific chemical species, are combined to evaluate the performance of both AP and OP.

The software used to carry out the MFA is the STAN (published by TU Wien, Institute for Water Quality, Resource and Waste Management) that is a freeware that helps to perform material flow analysis according to the Austrian standard ÖNorm S 2096 (Material flow analysis-application in waste management). Each balance is performed with reference to a same block diagram on different layers: one of these is dedicated to the balance of "goods" (in this case, the total mass of reactants and products involved in the AP and OP) and the others to different single substances (i.e. carbon, hydrogen, oxygen, nitrogen, etc.).
The calculation procedure adopted includes the following steps:

- Determination of the amount of the pre-treated $A$. donax utilised in the hydrolysis step of the AP and the transfer coefficients (TC) applying the MFA to the hydrolysis and fermentation units involved in the test FB4. The TCs was calculated as following:

$T C_{F, x}=\frac{W_{F, x}}{W_{F^{I N}}}$

where $\mathrm{TC}_{F_{x}}$ is the $\mathrm{TC}$ of the considered flow, $W_{F, x}$ is the mass of the considered flow and $W_{F^{\mathrm{IN}}}$ is the mass of the input flow to the considered process unit.

- Determination of the amount of virgin biomass fed into the pre-treatment unit of the OP on the basis of sugars involved in the AP, i.e. glucose and xylose produced during the hydrolysis step and pure glucose added during the fermentation process. The amount of biomass entering the $\mathrm{OP}\left(W_{A D-O P}\right)$ was calculated using the following equation:

$W_{\mathrm{AD}-\mathrm{OP}}=\frac{W_{\mathrm{Glu}-\mathrm{AP}}+W_{\mathrm{Glu}-\mathrm{Add}}+W_{\mathrm{Xyl}-\mathrm{AP}}}{X_{\mathrm{Glu}-\mathrm{AP}}+X_{\mathrm{Xyl}-\mathrm{AP}}}$,

where $W_{\text {Glu-AP }}$ and $W_{\text {Xyl-AP }}$ are glucose and xylose produced during the hydrolysis step of the AP, $W_{\text {Glu- }}$ Add is the glucose added during the test FB4 and $X_{\text {Glu- }}$ AP and $X_{\mathrm{Xyl}-\mathrm{AP}}$ are the fractions of glucose and xylose produced during the hydrolysis step of the AP;

- Definition of the quantified flow diagram of the OP that uses biomass as the only carbon source.

In order to ensure similar operating conditions of the two processes (AP and OP), the amounts of the reagents used (MH medium, carbon dioxide, yeast extract and ammonium hydroxide) and the reaction volume were kept constant (same concentration). Also acetic, formic and lactic acid by products were considered in the calculations.

\section{Results and discussion}

Evaluation of $A$. donax saccharification experiments

Currently, one of the major targets for the biotechnological production of succinic acid is cost reduction through the use of lignocellulosic feedstocks as raw materials. In the present paper a strategy combining steam explosion with enzymatic hydrolysis demonstrated a degree of cellulose and hemicellulose solubilization from $A$. donax biomasses of about $79 \pm 8$ and $55 \pm 5 \%$, according to Eqs. 1 and 2 "Enzymatic hydrolysis of $A$. donax" section, respectively. The concentrations of glucose and xylose found in the hydrolysate, together with the 
conversion efficiencies, are reported in Table 1. A. donax was recently attracting growing interests as renewable material for the production of value-added products, not only for economic aspects, but also for its cultivation ease and status of non-food/waste crop. Giacobbe and collaborators [21] also evaluated the saccharification of $A$. donax pretreated biomass and developed a new purified enzyme cocktail that achieved 62 and 63\% conversion of glucan and xylan, respectively. Combined dilute acidic hydrolysis and enzymatic hydrolysis on the recovered $A$. donax solid residue showed a 94 and $70 \%$ conversion efficiency of xylans and glucans, respectively [15]. Results obtained in this work are, therefore, in line with those reported in the literature.

\section{Performance of B. succiniciproducens BPP7 on A. donax hydrolysates in fed-batch fermentations on the pre-pilot scale}

Hydrolysed $A$. donax was used for fed-batch experiments on the pre-pilot scale. Different experimental conditions regarding the preparation of the feed solution, the profile used for its administration and the ratio of fed glucose to xylose, were analysed. When using a feed solution composed of $A$. donax supplemented with glucose and xylose (Fed-batch 1 and 2, Fig. 1, Table 2) an average production of $24 \pm 4 \mathrm{~g} / \mathrm{L}$ of succinic acid was achieved in the medium. In both cases, however, a high concentration of glucose and xylose of about $9 \pm 1$ and $4 \pm 1 \mathrm{~g} / \mathrm{L}$, respectively, was accumulated in the medium by the end of the experiment (Table 2); the addition during the second experiment (FB2) of a lower amount of total sugars $(33 \mathrm{~g} / \mathrm{L}$ vs $55 \mathrm{~g} / \mathrm{L})$, due to the slower feed rate $(0.54 \mathrm{~g} / \mathrm{L} \mathrm{h}$ vs $1.20 \mathrm{~g} / \mathrm{L} \mathrm{h}$ ), resulted in a $40 \%$ higher yield of succinic acid on consumed sugars equal to $0.89 \mathrm{~g} / \mathrm{g}$, to the detriment of productivity $(0.40 \mathrm{~g} / \mathrm{L}$ h vs $0.56 \mathrm{~g} / \mathrm{L} \mathrm{h})$; however, a quite high concentration of glucose and xylose was found throughout the process, still indicating an overload in that conditions (Fig. 1). When further decreasing the feed rate to $0.24 \mathrm{~g} / \mathrm{L} \mathrm{h}$ of $A$. donax supplemented with glucose only (FB 3, Fig. 1, Table 2) no accumulation of glucose and xylose in the medium was observed. Twenty-four $\mathrm{g} / \mathrm{L}$ of succinic acid were produced after $48 \mathrm{~h}$ of growth with a $Y_{\mathrm{SA} / \mathrm{Gl}+\mathrm{Xy}}$ of $0.79 \mathrm{~g} / \mathrm{g}$ and a productivity of $0.5 \mathrm{~g} / \mathrm{L} \mathrm{h}$ (Table 2). The highest concentration of succinic acid, equal to $37 \mathrm{~g} / \mathrm{L}$, was reached when adding pure glucose, during the fed-batch phase, at a constant rate of $0.8 \mathrm{~g} / \mathrm{L} \mathrm{h}$. The process lasted $43 \mathrm{~h}$ and resulted in a $Y_{\mathrm{SA} / \mathrm{Gl}+\mathrm{Xy}}$ of $0.9 \mathrm{~g} / \mathrm{g}$ and a productivity of about $0.9 \mathrm{~g} / \mathrm{L} \mathrm{h}$. However, also under these conditions, the accumulation of 4.78 and $2.11 \mathrm{~g} / \mathrm{L}$ of glucose and xylose, respectively, was still observed. A similar final concentration of SA $(33.8 \mathrm{~g} / \mathrm{L})$ was previously obtained in fed-batch experiments on nanofiltered spent sulphite liquor with a slightly lower yield of SA on consumed sugars $(0.58 \mathrm{~g} / \mathrm{g})$ and productivity $(0.48 \mathrm{~g} / \mathrm{L} \mathrm{h})$ [22]. Overall, B. succiniciproducens BPP7 demonstrated a significantly lower sugar consumption rate during the fed-batch phase; in fact, only feeding about $0.24 \mathrm{~g} / \mathrm{L} \mathrm{h}$ of total sugars did not lead to sugar accumulation in the medium. The different ratios of A.donax-derived to pure sugars used in FB experiments could not be related to the different fermentation results. It seems, however, that higher glucose:xylose ratios reduced the total acid by-product to succinic acid proportion (Table 3); these data are consistent with those reported by Pateraki and collaborators [22] that observed a higher total acid (TA)/SA ratio, equal to $0.65 \mathrm{~g} / \mathrm{g}$, when growing B. succiniciproducens on a semidefined medium containing $73 \%$ xylose and $11 \%$ glucose. The authors also observed increased TA/SA values $(0.9-1 \mathrm{~g} / \mathrm{g})$ in spent sulphite liquor-based media, indicating that the inhibitors present in lignocellulosic substrates stimulate the production of other acid by-products [22]. Although the use of lignocellulose hydrolysates as sole $\mathrm{C}$ source is more suitable for the development of sustainable fermentation processes, concentrated A. donax would also contain high concentrations of inhibitory molecules such as acetic acid and phenolic compounds that were previously shown to strongly delay the growth of

Table 1 Sugar concentrations and saccharification efficiency after steam pretreatment and enzymatic hydrolysis, calculated according to Eq. 1 and 2

\begin{tabular}{|c|c|c|c|c|c|c|}
\hline & $\begin{array}{l}\text { A. donax biomass (Kg } \\
\text { dry biomass) }\end{array}$ & Total volume (L) & Glucose $^{a}(g / L)$ & Xylose $^{a}(\mathrm{~g} / \mathrm{L})$ & $\begin{array}{l}\text { Cellulose } \\
\text { conversion (\%) }\end{array}$ & $\begin{array}{l}\text { Hemicellulose } \\
\text { conversion (\%) }\end{array}$ \\
\hline FB1 & 6.4 & 65.5 & 33.0 & 16.6 & 89.9 & 58.2 \\
\hline FB2 & 6.0 & 61.4 & 26.5 & 14.7 & 72.2 & 51.5 \\
\hline FB3 & 6.4 & 65.5 & 27.0 & 14.0 & 73.6 & 49.1 \\
\hline FB4 & 6.4 & 65.5 & 29.0 & 17.0 & 79.0 & 59.6 \\
\hline Mean & & & 28.9 & 15.6 & 78.7 & 54.6 \\
\hline SD & & & 2.9 & 1.4 & 8.1 & 5.1 \\
\hline
\end{tabular}

${ }^{a}$ Indicates the concentration of glucose and xylose found in the hydrolysate 

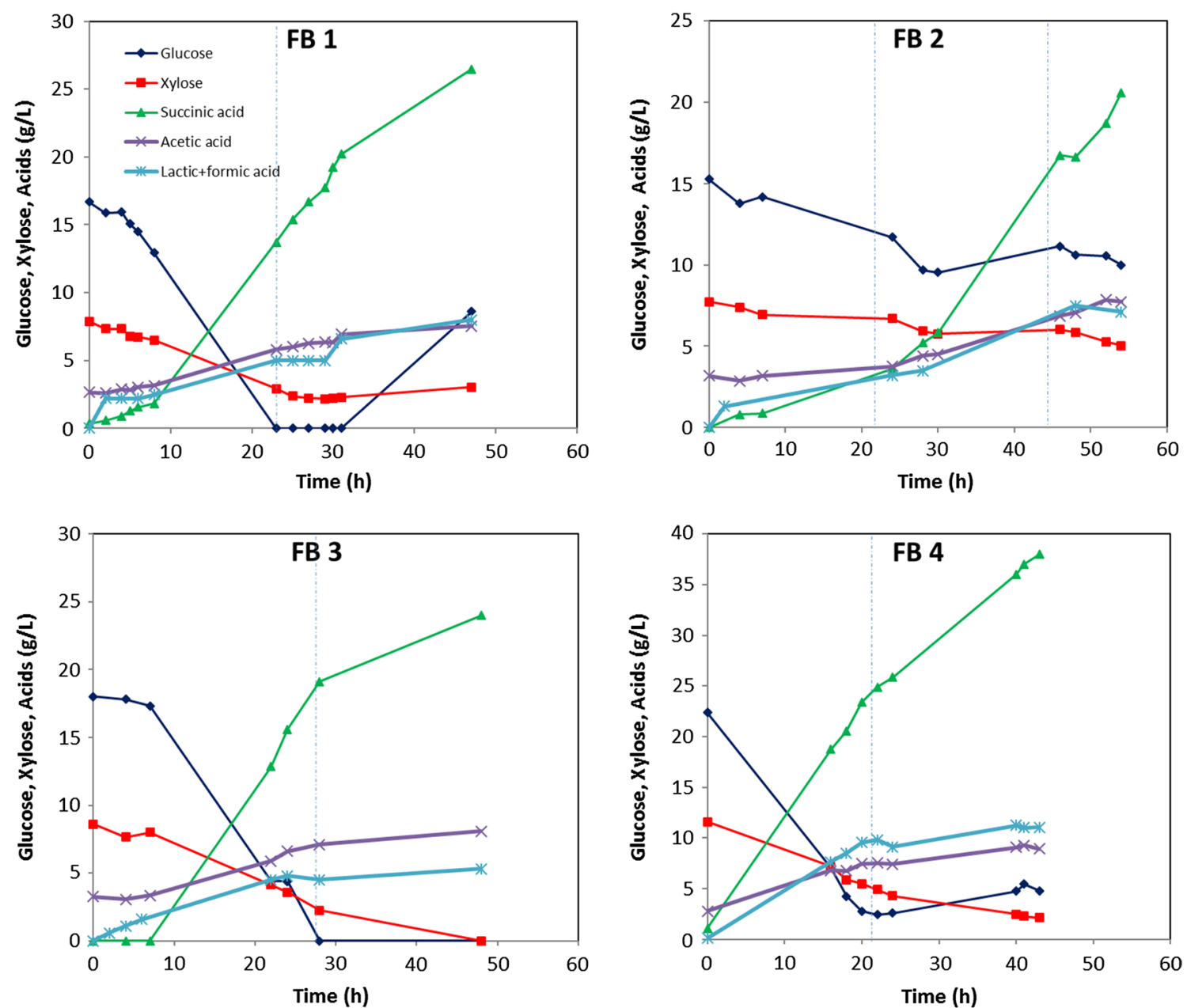

Fig. 1 Pilot scale FB experiments. Production of succinic acid from B. succiniciproducens in fed-batch experiments on the $150 \mathrm{~L}$ scale with an initial working volume of $70 \mathrm{~L}$. The vertical dotted line indicates FB start (In FB2 also the end of the feeding phase is indicated). Feed type: FB1, A. donax + glucose + xylose (5:1); FB2, A. donax + glucose + xylose (1.9:1); FB3, A. donax + glucose; FB4, pure glucose. Total sugars feed rate: FB1, 1.2 g/L h; FB2, $0.5 \mathrm{~g} / \mathrm{L}$ h; FB3, $0.2 \mathrm{~g} / \mathrm{L} \mathrm{h} ; \mathrm{FB} 4,0.8 \mathrm{~g} / \mathrm{Lh}$

B. succiniciproducens [10]. By comparing FB1 and FB2 it seems that SA production was favoured by a higher glucose:xylose ratio in the feed (5:1, FB1 vs 2:1, FB2 mock A. donax ratio) probably due to the faster consumption rate of glucose compared to xylose in co-presence. In FB2, probably the sugar overload and the higher xylose supply also addressed metabolism towards a higher production of lactic and formic acid byproducts as indicated by the ratios reported in Table 3. Overall, the best final titer and productivity of succinic acid were achieved when pure glucose was fed to the culture, indicating that, as for A. succinogenes, also B. succiniciproducens produces more SA on hydrolysates that contain more glucose than xylose [23, 24].

A global mass balance was performed on all fermentation experiments considering the fractions of cellulose and hemicelluloses present in the treated dry biomass and the maximal theoretical yield of succinic acid on glucose and xylose consumed (Eq. 3), resulting in a fermentation efficiency ranging between 47 and 75\% (Table 3). The fermentability of $A$. donax was previously evaluated for the production of second-generation bioethanol demonstrating an enzymatic conversion efficiency of the cellulose (contained in already partially delignified cellulignin) to glucose of about $52 \%$, and a fermentation efficiency from glucose to ethanol of about 40\% [25]. Compared to the previously developed batch process in our lab [10], the concentration of succinic acid, the volumetric productivity $(r)$ and the $Y_{\mathrm{SA} / \mathrm{Gl}+\mathrm{Xy}}$ of the process were improved by 2.4-, 2.7- and 1.3-fold, respectively. In batch conditions on corn stover B. succiniciproducens produced $30 \mathrm{~g} / \mathrm{L}$ of product with a yield of about $0.69 \mathrm{~g} / \mathrm{g}$ on consumed sugars [11]. Recently, an efficient fed-batch process with immobilized cell cultures reached $45 \mathrm{~g} / \mathrm{L}$ 


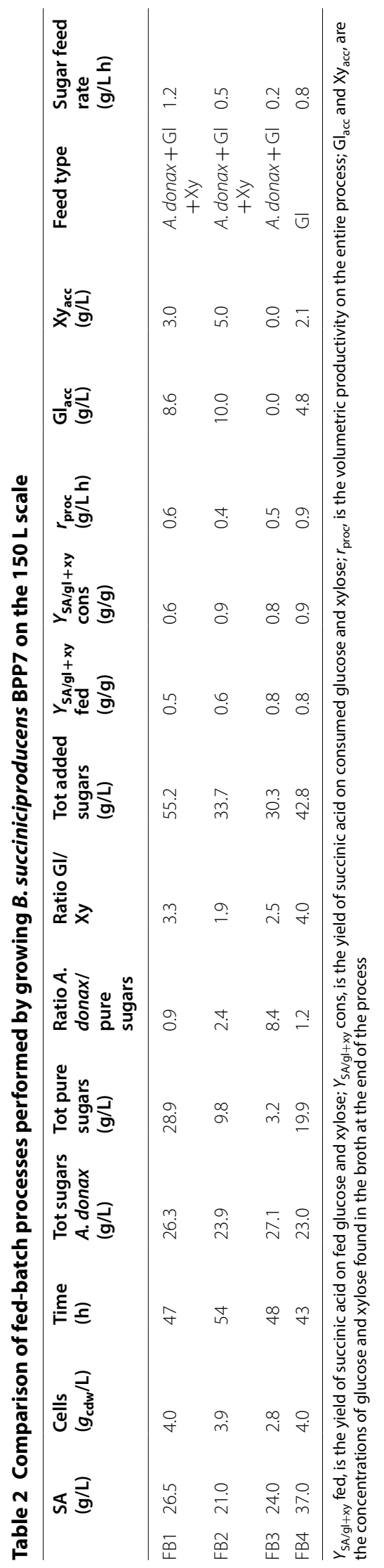




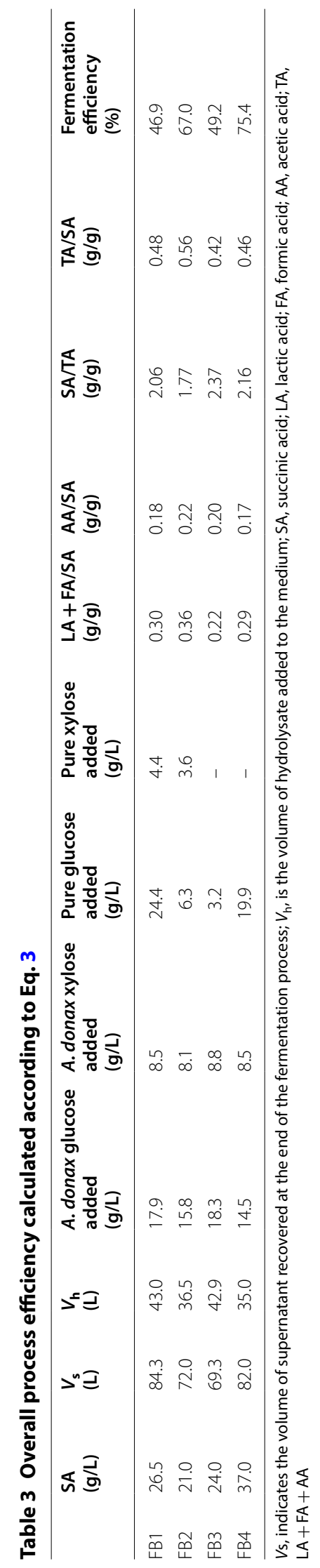


of succinic acid in $80 \mathrm{~h}$ from spent sulphite liquor [12]. Productivity, however, was about 55\% lower compared to that described in the present work.

\section{Succinic acid growth inhibition}

Bottle experiments on MH medium supplemented with increasing concentrations of succinic acid in the medium showed a decrease of the total biomass produced and of the specific growth rate $(\mu)$, calculated as linear regression of OD measurements over time during the first $6 \mathrm{~h}$ of growth. The experimental data were fitted to the Luong-model $[26,27]$ exponential inhibition equation:

$$
\mu=\mu_{\max }\left(1-\frac{P}{P_{\max }}\right)^{n_{p}}
$$

where $\mu_{\max }$ is the maximum specific growth rate calculated in the absence of succinic acid in the medium, $P$ is the concentration of product (succinic acid), $P_{\max }$ is the critical product concentration (when $P=P_{\max }, \mu=0$ ) and $\mathrm{n}_{\mathrm{p}}$ is the inhibition constant (for non competitive inhibition $\left.n_{p}>0\right)$. We found a $P_{\max }$ of $60 \mathrm{~g} / \mathrm{L}$ and a $\mu_{\max }$ equal to $0.55 \mathrm{~h}^{-1}$ determined experimentally (Fig. 2). A regression coefficient $\left(R^{2}\right)$ equal to 0.98 was found analysing data with Sigma plot.

Lin and collaborators proposed a kinetic model for $A$. succinogenes that considers substrate and product inhibition and found a threshold for SA inhibition equal to $104 \mathrm{~g} / \mathrm{L}$ [28]. This characterization of the strain physiology was not performed for B. succiniciproducens up to date, and it is interesting to notice that a $60 \%$ reduction of the growth rate was already observed in the presence of $30 \mathrm{~g} / \mathrm{L}$ of succinic acid in the medium.

\section{Performance assessment of an optimized process for SA production}

This section evaluated another aspect of industrial development that was not considered up to date; in fact, only few works are addressed to the performance assessment of the whole SAPP.

In particular, the experimental results obtained from the FB4 experiment, literature data and those generated by the MFA and by the characterization of specific process streams were combined to evaluate the performance of a facility that encloses the main steps involved in the SA production process, i.e. biomass pre-treatment, hydrolysis, fermentation and purification. The OP proposed uses $A$. donax as the only carbon source. The MFA analysis consists in a systematic assessment of the flows and stocks of materials and elements within a system defined in space and time. In particular, it connects the sources, the pathways and the intermediate and final sinks of each species in a specific process [29]. These characteristics make MFA a flexible decision support tool attractive for different application fields, as showed by its utilization in process evaluation of waste thermochemical conversion and recycling options [30,31] and in waste management planning [32]. Figure 3 shows the layer of total mass as a result of the MFA applied to the FB4 experiment, i.e. the quantified block diagram on dry basis of the hydrolysis and fermentation units. The inputs to the process units are: pre-treated biomass, $\mathrm{MH}$ medium, carbon dioxide, glucose, yeast extract and ammonium hydroxide. The output streams are: non-hydrolysed biomass, succinic acid and by-products (unconverted sugars, other acids, microorganism, inorganics, etc.) produced during the fermentation step. Each flow in input to or in output from a specific unit is identified with a black arrow if the specific data were measured, or by a grey arrow if the data were obtained by means of the material balance of the MFA. The quantified block diagram displayed in Fig. 3 shows that the TC related to the flow $F_{3}\left(\mathrm{TC}_{F, 3}\right)$ is 0.54 . Since the overall pre-treated biomass was used for the hydrolysis process, the combined efficiency of the pre-treatment and hydrolysis processes is $54 \%$ ( $1.85 \mathrm{~kg}$ of hydrolysed biomass). Thus, $\mathrm{TC}_{F, 2}$ is 0.46 ; this means that the unconverted biomass is $1.57 \mathrm{~kg}$. As a consequence, the amount of the pre-treated biomass, which corresponds to the virgin biomass fed to the process, is $3.42 \mathrm{~kg}$. The output from the fermentation unit is $7.28 \mathrm{~kg}$. During this process $3.03 \mathrm{~kg}$ of SA and $4.25 \mathrm{~kg}$ of by-products are generated.

As previously mentioned, the feedstock cost of biochemicals production is one of the main ones of the entire manufacturing process; therefore making SA production more economically and environmentally sustainable requires the use of raw materials, such as lignocellulosic biomass, as only carbon source. For this reason, we also evaluated a process based on the use of $A$. donax as only carbon source by translating the amount of pure glucose added during the developed FB fermentation process into additional virgin biomass (Fig. 4). The application of the Eq. 4 shows that $7.53 \mathrm{~kg}$ of virgin biomass (i.e. the flow $F_{1}$ of Fig. 4) should be pre-treated and hydrolysed to produce the total amount of sugars $(3.54 \mathrm{~kg})$ necessary in the AP (sugars generated during the hydrolysis step: $1.02 \mathrm{~kg}$ of glucose and $0.59 \mathrm{~kg}$ of xylose; glucose added during the fermentation process: $1.93 \mathrm{~kg}$ ). The flows $F_{3}$ and $F_{4}$ are generated by utilising the TCs of the hydrolysis unit of the AP ( 0.46 and 0.54 for $F_{3}$ and $F_{4}$, respectively), while the inputs $F_{5,7-9}$ are the same of Fig. 3.The last process unit considered in the OP involves purification and separation steps which generate a highly purified SA stream, according to literature data [20]. In particular, it consists of a reactive extraction, a vacuum distillation and a crystallization process that ensure a SA purity of $98 \%$ and a yield of $73.1 \%$, as indicated by the authors. As 


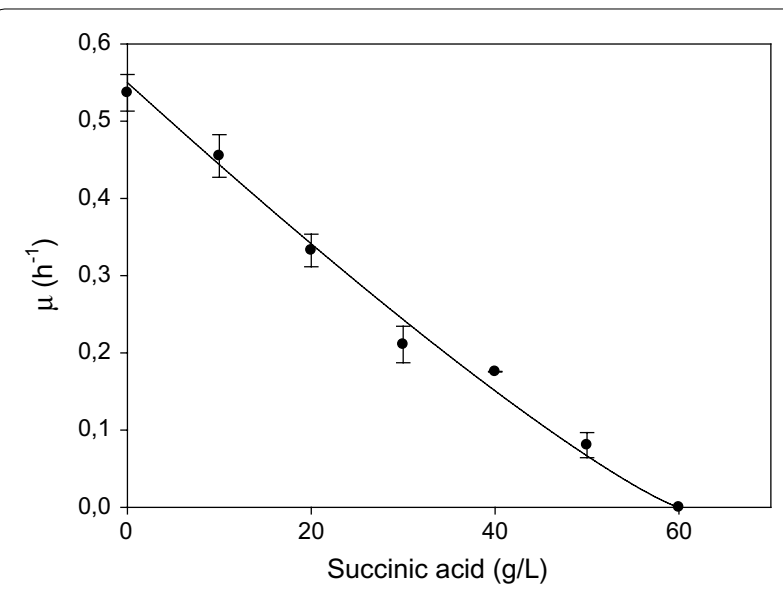

Fig. 2 Product inhibition. Evaluation of succinic acid inhibition on the growth of B. succiniciproducens in bottle experiments with an initial glucose concentration of $10 \mathrm{~g} / \mathrm{L}, \mathrm{pH} 6.5$ and temperature of $37^{\circ} \mathrm{C}$

a result, the flow $F_{12}$ is equal to $2.22 \mathrm{~kg}$ (constituted of $98 \%$ of succinic acid), while the flow $F_{11}$ consist of $5.35 \mathrm{~kg}$ of process by-products (unconverted sugars, other acids, microorganism, inorganics, etc.) and of the unrecovered SA. The main results of the MFA application to the OP proposed are that this process yields $29.48 \%$ of purified SA per kilogramme of virgin biomass. On the other hand, the by-products amount to $79.80 \%$ of the total input. The $48.46 \%$ of this should be disposed $\left(F_{11}\right)$, while the $31.34 \%$ is unconverted biomass of the hydrolysis step $\left(F_{3}\right)$. Considering the proposed OP in a commercial scale, this process residue (composed mainly of lignin) could represent a valuable feedstock for bioenergy and biochemicals' production in a view of biorefinery complexes development [33]. It must be highlighted that the considered OP utilized the highest conversion factor of sugars to SA obtained from the fermentation test FB4. As can be deduced from Table 3, the mass conversion factors range from about 50 to $80 \%$. Considering, as a conservative evaluation of SA production, the conversion factor obtained using the data from all the experiments that we conducted (FB1-2-3-4), the yield of SA decreases from 30 to $25 \%$ (Additional file 1: Figure S1), which demonstrates the robustness of our chosen MFA approach and confirms the validity of using $B$. succiniciproducens with $A$. donax as substrate with the objective of achieving a sustainable process for the production of succinic acid.

\section{Evaluation on the valorisation of residual and global carbon balance}

The results of proximate and ultimate analysis are reported in Table 4. Both the hydrolysed A. donax and the solid after fermentation show a very high moisture content, while as expected the presence of moisture of the microorganism is reduced according to the nature of the material. The concentration of the $\mathrm{N}$ in the solid

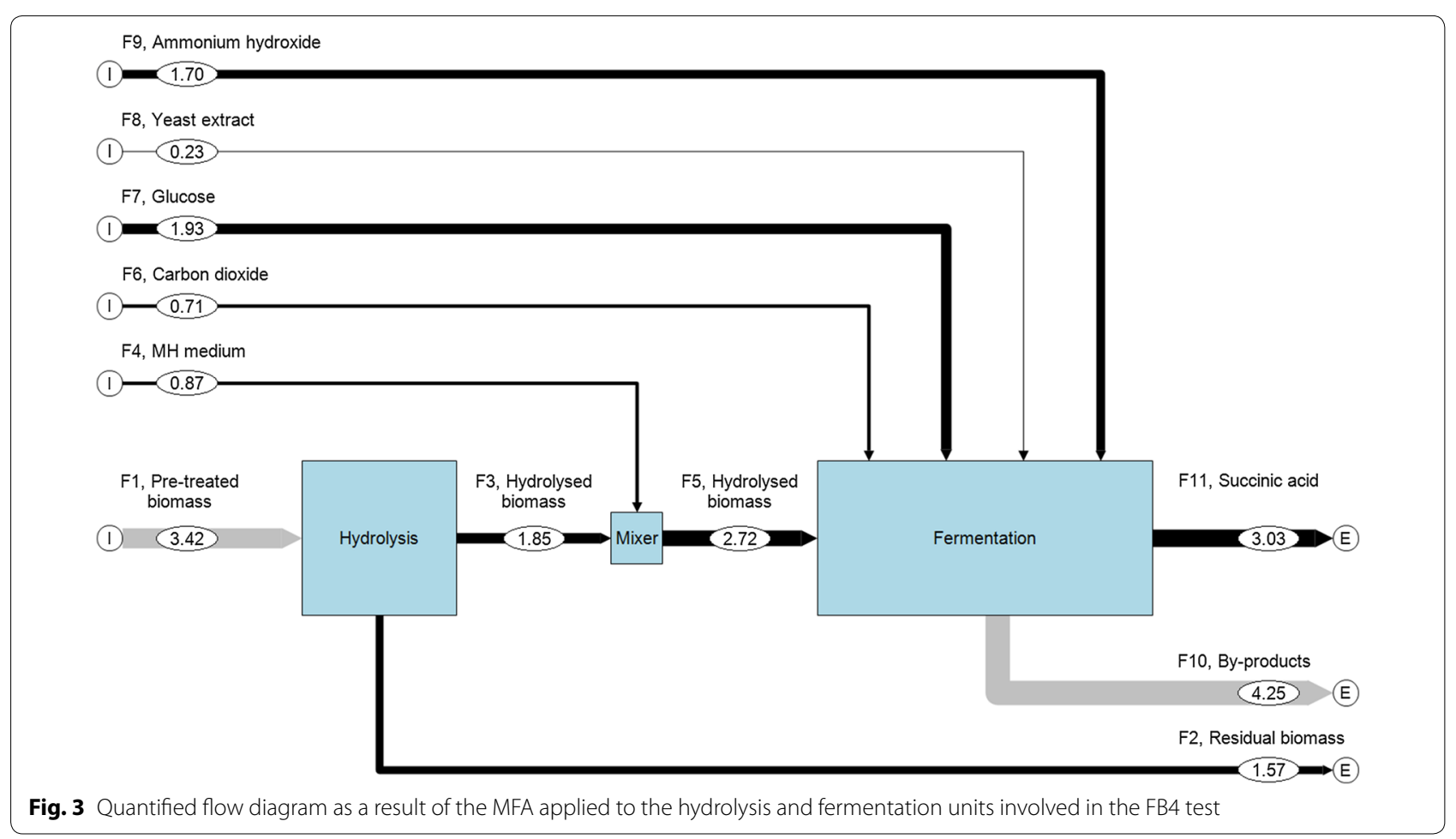




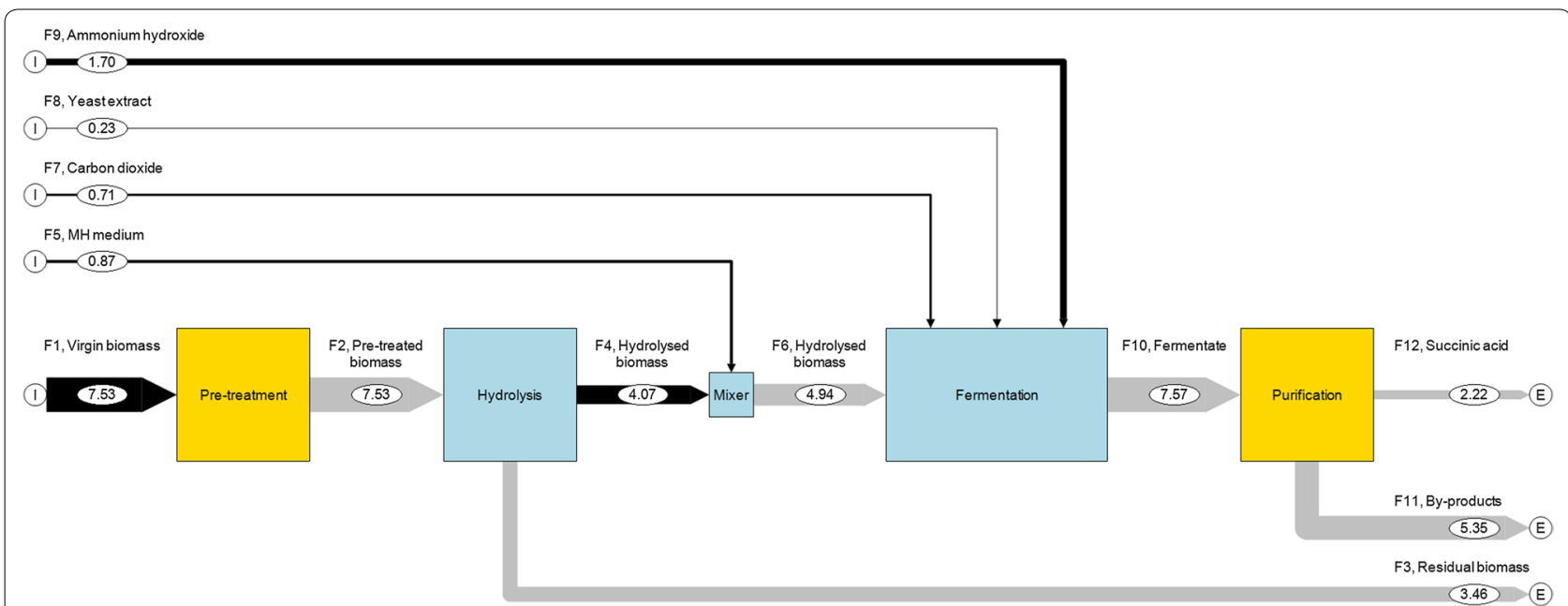

Fig. 4 Quantified flow diagram as a result of the MFA applied to the OP

Table 4 Proximate and ultimate analysis

\begin{tabular}{lccc}
\hline Proximate analysis, \% $_{\text {wt, ar }}$ & Hydrolysed A. donax & B. succiniciproducens & $\begin{array}{l}\text { Solid } \\
\text { after fermentation }\end{array}$ \\
\hline Moisture & 70.88 & 5.5 & 76.43 \\
Volatile matter & 19.37 & 79.3 & 19.44 \\
Fixed carbon & 6.80 & 7.6 & 2.81 \\
Ash & 2.95 & 7.6 & 1.32 \\
Ultimate analysis, w $_{\text {wt, ar }}$ & & & 11.40 \\
C & 12.78 & 39.15 & 1.63 \\
H & 0.60 & 6.03 & 2.78 \\
N & 0.88 & 10.80 & 6.44 \\
O (by diff.) & 11.91 & 30.92 & 1.71 \\
H/C (molar ratio) & 0.56 & 1.85 & 0.42 \\
O/C (molar ratio) & 0.70 & 0.59 & 8.64 \\
C/ash (weight ratio) & 4.33 & 5.15 & \\
\hline
\end{tabular}

coming from the fermentation step is about two times higher than that of the starting material while a reduction of the ash concentration is observed. The $\mathrm{H} / \mathrm{C}$ and $\mathrm{O} / \mathrm{C}$ ratio evaluated for the hydrolysed $A$. donax (Table 4) and compared with those reported by Chen and collaborators [34] $(1.67,1.60$ and $1.19-1.53$ and to $0.83,0.8$ and $0.47-$ 0.36 for cellulose, hemicellulose and lignin, respectively) show that in the sample a fraction of cellulose ad hemicellulose is still present in addition to the lignin.

On the basis of the proximate and ultimate analysis a preliminary analysis on the reliability of the combustion process using both the hydrolysed $A$. donax and the residual of the fermentation as fuel was carried out. More specifically, the adiabatic temperature, i.e. neglecting the external heat dispersion, considering different excess air factors and assuming different conversion efficiency (Fig. 5) has been evaluated. Curves in Fig. 5 indicate that the adiabatic temperature is almost always lower than $800{ }^{\circ} \mathrm{C}$ suggesting that an autothermal combustion process is not sustainable. In particular, it is possible to obtain an adiabatic temperature higher than $800{ }^{\circ} \mathrm{C}$ only operating the reactor at very low air excess factors and considering a thermal efficiency not lower than 0.8 using the starting material (the hydrolysed $A$. donax). If the residue of the fermentation step would be used as fuel, a more restrictive condition should be adopted to obtain an adiabatic temperature of $800{ }^{\circ} \mathrm{C}$, more specifically an excess factor lower than $10 \%$ and only for the thermal efficiency equal to one can be used. The latter result is in agreement with the further conversion of biomass in the fermentation step with a consequent reduction of the energy content of the residual material. The results suggest that a pre-treatment to reduce the moisture content is necessary before the combustion process. In the 


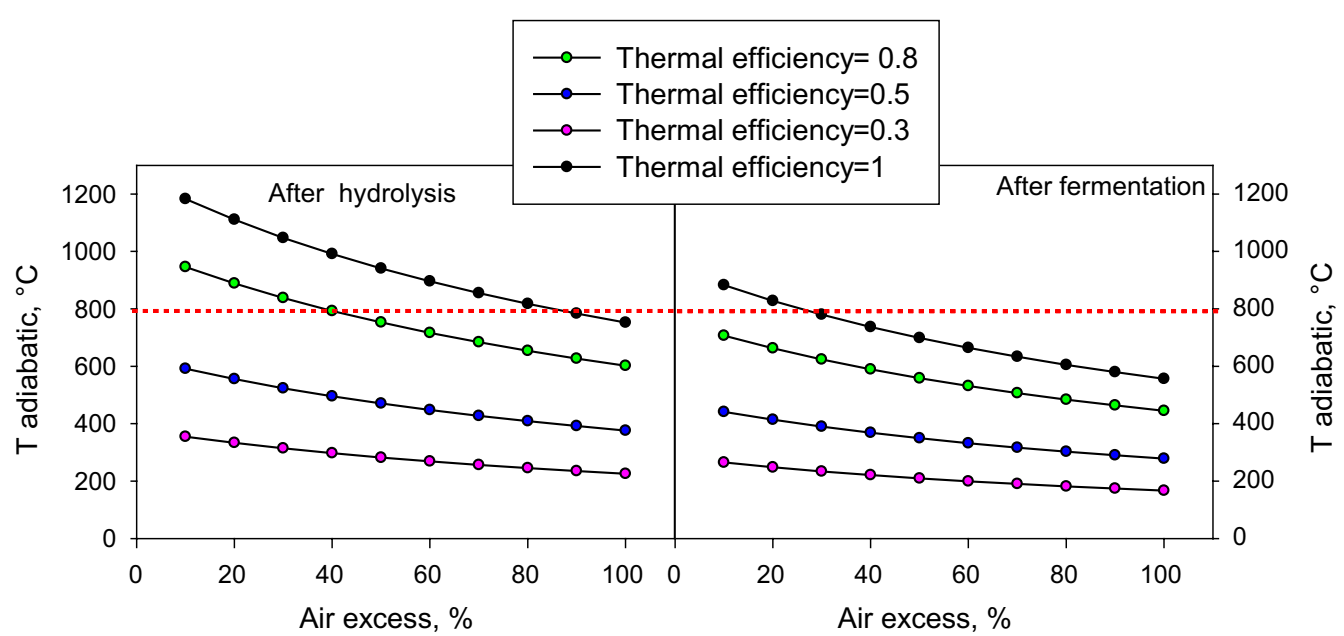

Fig. 5 Adiabatic temperature as function of the excess air factors and for different thermal efficiencies

utilization of the residual materials as fuel for a combustion process the other critical point is the high concentration of $\mathrm{N}$ in the samples since a high concentration of nitrogen oxides (fuel NOx) is expected. A basic calculation of the amount of $\mathrm{NO}_{2}$ equivalent emitted during the combustion was done. In particular, the concentration of $\mathrm{NO}_{2}$ was estimated considering a fuel nitrogen conversion between 10 and $40 \%$, in agreement with previous results [35]. The authors performed fluidized bed combustion experiments with a high $\mathrm{N}$ concentration fuel such as olive husk and considered the air excess necessary to obtain a concentration of oxygen equal to $11 \mathrm{vol} \%$ at the exit of the gas. The value of $\mathrm{NO}_{2}$ concentration in the emitted gas obtained considering a conversion of only $10 \%$ (1378 and $3528 \mathrm{mg} / \mathrm{Nm}^{3}$ for hydrolysed $A$. donax and the residual of fermentation, respectively) is exceeding the threshold prescribed by the Italian normative $\left(500 \mathrm{mg} / \mathrm{Nm}^{3}\right.$ of $\mathrm{NO}_{2}$ at an $\mathrm{O}_{2}$ concentration of $11 \%$ vol. D.Lgs.33 Aprile 2006 n. 152) suggesting that a post treatment section for the abatement of NOx should be included.

\section{Conclusion}

Succinic acid production from B. succiniciproducens on $A$. donax was studied with different FB experiments on the pre-pilot scale, with a highest process efficiency of about $75 \%$ considering the hydrolysis and fermentation process units. Best experimental results were analysed by material flow analysis to evaluate another aspect of industrial development and assess the performance of the entire production process. Results indicated the obtainment of $88.5 \%$ succinic acid per $\mathrm{kg}$ of biomass used and $52 \%$ of product on the total output generated. Considering an optimized process that uses $A$. donax as only
C source, data indicated a potential yield of about $30 \%$ of product and an unconverted residue of $31 \%$ mainly composed of lignin, a potentially valuable feedstock for bioenergy and biochemicals' production.

\section{Additional file}

Additional file 1: Figure S1. Quantified flow diagram as a result of the MFA applied to the OP by using an average fermentation efficiency of all fermentation tests performed (FB1-2-3-4).

\section{Abbreviations}

SA: succinic acid; FB: fed-batch; MFA: material flow analysis; OP: optimized process; SAPP: succinic acid production process; AP: actual process.

\section{Authors' contributions}

DC and CS conceived the work; DC and SD performed shakeflask and fermentation experiments and efficiency data analysis; LZ performed MFA analysis; LL performed A. donax hydrolysis; GR performed residual valorisation experiments; OP provided the strain; VF provided the preliminary protocol for hydrolysis. All authors read and approved the final manuscript.

\section{Author details}

${ }^{1}$ Department of Experimental Medicine, University of Campania L. Vanvitelli, Via de Crecchio 7, 80138 Naples, Italy. ${ }^{2}$ Department of Environmental, Biological and Pharmaceutical Sciences and Technologies, University of Campania L. Vanvitelli, Via Vivaldi 43, 81100 Caserta, Italy. ${ }^{3}$ Institute of Biomolecular Chemistry (ICB), National Research Council, Via Campi Flegrei, 34, 80078 Pozzuoli, Naples, Italy. ${ }^{4}$ Istituto di Ricerche sulla Combustione (IRC), National Research Council, Piazzale Tecchio 80, 80125 Naples, Italy. ${ }^{5}$ Department of Agricultural Sciences, Division of Microbiology, University of Naples Federico II, Via Università 100, 80055 Portici, Naples, Italy. ${ }^{6}$ Department of Chemical Sciences, University of Naples Federico II, Naples, Italy.

\section{Acknowledgements}

We gratefully thank Michela Inverso for the help provided for HPLC analyses and Paola Brachi for the help provided on the valorisation of residual and global carbon balance.We also thank Novozymes (Denmark) for providing the enzyme mix. 


\section{Competing interests}

The authors declare that they have no competing interests.

\section{Availability of data and materials}

The data sets used and/or analysed during the current study are available from the corresponding authors on reasonable request.

\section{Consent for publication}

Not applicable.

\section{Ethics approval and consent to participate} Not applicable.

\section{Funding}

This work was supported by the Ministero dell'Università e della Ricerca Scientifica [PON03PE_00107_1/1 "Development of green technologies for production of BIOchemicals and their use in preparation and industrial application of POLImeric materials from agricultural biomasses cultivated in a sustainable way in Campania region-BioPolis"] funded in frame of the Operative National Programme Research and Competitiveness 2007-2013 D. D. Prot. n. 713/ Ric. del 29.10.2010. The costs of the open access publication were supported by the "Programma Valere 2017" organised by the University of Campania L. Vanvitelli (Naples, Italy).

\section{Publisher's Note}

Springer Nature remains neutral with regard to jurisdictional claims in published maps and institutional affiliations.

Received: 22 November 2018 Accepted: 25 January 2019 Published online: 04 February 2019

\section{References}

1. Choi S, Song CW, Shin JH, Lee SY. Biorefineries for the production of top building block chemicals and their derivatives. Metabol Eng. 2015;28:223-39.

2. Becker J, Lange A, Fabarius J, Wittmann C. Top value platform chemicals: bio-based production of organic acids. Curr Opin Biotechnol. 2015:36:168-75.

3. Cok B, Tsiropoulos I, Roes AL, Patel MK. Succinic acid production derived from carbohydrates: an energy and greenhouse gas assessment of a platform chemical toward a bio-based economy. Biofuel Bioprod Bioref. 2014;8:16-29.

4. E4tech 2015: From the Sugar Platform to biofuels and biochemicals. Final report for the European Commission Directorate-General Energy $N^{\circ}$ ENER/C2/423-2012/SI2.673791.

5. Akhtar J, Idris A, Abd Aziz R. Recent advances in production of succinic acid from lignocellulosic biomass. Appl Microbiol Biotechnol. 2014;98(3):987-1000. https://doi.org/10.1007/s00253-013-5319-6.

6. Zheng P, Dong JJ, Sun ZH, Ni Y, Fang L. Fermentative production of succinic acid from straw hydrolysate by Actinobacillus succinogenes. Bioresour Technol. 2009;100:2425-9.

7. Kim DY, Yim SC, Lee PC, Lee WG, Lee SY, Chang HN. Batch and continuous fermentation of succinic acid from wood hydrolysate by Mannheimia succiniciproducens MBEL55E. Enzyme Microb Technol. 2004:35:648-53.

8. Palmqvist E, Hahn-Hagerdal B. Fermentation of lignocellulosic hydrolysates. II: inhibitors and mechanisms of inhibition. Bioresour Technol. 2000;74:25-33.

9. Ventorino V, Robertiello A, Cimini D, Argenzio O, Schiraldi C, Montella S, Faraco V, Ambrosanio A, Viscardi S, Pepe O. Bio-based succinate production from Arundo donax hydrolysate with the new natural succinic acid-producing strain Basfia succiniciproducens BPP7. Bioenerg Res. 2017; 10:488-98.

10. Cimini D, Argenzio O, D'Ambrosio S, Lama L, Finore I, Finamore R, Pepe O, Faraco V, Schiraldi C. Production of succinic acid from Basfia succiniciproducens up to the pilot scale from Arundo donax hydrolysate. Bioresour Technol. 2016;222:355-60. https://doi.org/10.1016/j.biort ech.2016.10.004
11. Salvachúa D, Smith H, St John PC, Mohagheghi A, Peterson DJ, Black BA, Dowe N, Beckham GT. Succinic acid production from lignocellulosic hydrolysate by Basfia succiniciproducens. Bioresour Technol. 2016;214:558-66.

12. Alexandri M, Papapostolou H, Stragier L, Verstraete W, Papanikolaou S, Koutinas AA. Succinic acid production by immobilized cultures using spent sulphite liquor as fermentation medium. Bioresour Technol. 2017;238:214-22

13. Garbero M, Ottonello P, Cotti CM, Ferrero S, Torre P, Cherchi F, Bonanni A. Improved biomass pretreatment process. 2010. WO 2010113129 A3.

14. Kuglarz M, Alvarado-Morales M, Karakashev D, Angelidaki I. Integrated production of cellulosic bioethanol and succinic acid from industrial hemp in a biorefinery concept. Bioresour Technol. 2016;200:639-47. https://doi.org/10.1016/j.biortech.2015.10.081.

15. Shatalov AA, Pereira H. Xylose production from giant reed (Arundo donax L.): modeling and optimization of dilute acid hydrolysis. Carbohydr Polym. 2012;87:210-7

16. Gunnarsson IB, Kuglarz M, Karakashev D, Angelidaki I. Thermochemical pretreatments for enhancing succinic acid production from industrial hemp (Cannabis sativa L.). Bioresour Technol. 2015;182:58-66. https:// doi.org/10.1016/j.biortech.2015.01.126.

17. Bradfield MFA, Mohagheghi A, Salvachúa D, Smith H, Black BA, Dowe N, Beckham GT, Nicol W. Continuous succinic acid production by Actinobacillus succinogenes on xylose-enriched hydrolysate. Biotechnol Biofuels. 2015:8:181-97. https://doi.org/10.1186/s13068-015-0363-3.

18. Van Heerden C, Nicol W. Continuous and batch cultures of Escherichia coli KJ134 for succinic acid fermentation: metabolic flux distributions and production characteristics. Microb Cell Fact. 2013;12:80-9.

19. Stelte W. Steam explosion for biomass pre-treatment, Resultat Kontrakt (RK) Report, Danish Technological Institute; 2013.

20. Huh YS, Jun YS, Hong YK, Song H, Lee SY, Hong WH. Effective purification of succinic acid from fermentation broth produced by Mannheimia succiniciproducens. Process Biochem. 2006:41:1461-5.

21. Giacobbe S, Balan V, Montella S, Fagnano M, Mori M, Faraco V. Assessment of bacterial and fungal (hemi)cellulose-degrading enzymes in saccharification of ammonia fibre expansion-pretreated Arundo donax. Appl Microbiol Biotechnol. 2016;100(5):2213-24. https://doi. org/10.1007/s00253-015-7066-3.

22. Pateraki C, Ladakis D, Stragier L, Verstraete W, Kookos I. Pretreatment of spent sulphite liquor via ultrafiltration and nanofiltration for bio-based succinic acid production. J Biotechnol. 2016;233:95-105. https://doi. org/10.1016/j.jbiotec.2016.06.027.

23. Zheng P, Fang L, Xu Y, Dong JJ, Ni Y, Sun ZH. Succinic acid production from corn stover by simultaneous saccharification and fermentation using Actinobacillus succinogenes. Bioresour Technol. 2010;101:7889-94

24. Li Q, Lei J, Zhang R, Li J, Xing J, Gao F, Gong F, Yan X, Wang D, Su Z, Ma G. Efficient decolorization and deproteinization using uniform polymer microspheres in the succinic acid biorefinery from bio-waste cotton (Gossypium hirsutum L.) stalks. Bioresour Technol. 2013;135:604-9. https ://doi.org/10.1016/j.biortech.2012.06.101

25. Lemons e Silva CF, Schirmer MA, Maeda RN, Barcelo CA, Pereira N Jr. Potential of giant reed (Arundo donax L.) for second generation ethanol production. Electron J Biotechnol. 2015;18:10-23.

26. Luong $\mathrm{JH}$. Kinetics of ethanol inhibition in alcohol fermentation. Biotechnol Bioeng. 1985;27(3):280-5.

27. Smita S, Ashok KS. Biological phosphate removal by model based fed-batch cultivation of Acinetobacter calcoaceticus. Biochem Eng J. 2008;40:227-32.

28. Lin SKC, Du C, Koutinas A, Wang R, Webb C. Substrate and product inhibition kinetics in succinic acid production by Actinobacillus succinogenes. Biochem Eng J. 2008;41(2):128-35. https://doi.org/10.1016/j. bej.2008.03.013.

29. Brunner $\mathrm{PH}$, Rechberger $\mathrm{H}$. Practical handbook of material flow analysis. Boca Raton: CRC Press LLC; 2004.

30. Mastellone ML, Zaccariello L. Metals flow analysis applied to the hydrogen production by catalytic gasification of plastics. Int J Hydrog Energy. 2013;38:3621-9.

31. Cremiato R, Mastellone ML, Tagliaferri C, Zaccariello L, Lettieri P. Environmental impact of municipal solid waste management using life cycle assessment: the effect of anaerobic digestion, materials recovery 
and secondary fuels production. Renew Energy. 2017;124:180-8. https ://doi.org/10.1016/j.renene.2017.06.033.

32. Zaccariello L, Cremiato R, Mastellone ML. Evaluation of municipal solid waste management performance by material flow analysis: theoretical approach and case study. Waste Manag Res. 2015;33(10):871-85.

33. Maity SK. Opportunities, recent trends and challenges of integrated biorefinery: part I. Renew Sus Energ Rev. 2015:43:1427-45.
34. Chen WH, Peng J, Bi XT. A state-of-the-art review of biomass torrefaction, densification and applications. Renew Sust Energ Rev. 2015;44:847-66.

35. Miccio F, Ruoppolo G, Russo S, Urciuolo M, De Riccardis A. Fluidized bed combustion of wet biomass fuel (Olive husks). Chem Eng Trans. 2014;37:1-6. https://doi.org/10.3303/CET1437001.
Ready to submit your research? Choose BMC and benefit from:

- fast, convenient online submission

- thorough peer review by experienced researchers in your field

- rapid publication on acceptance

- support for research data, including large and complex data types

- gold Open Access which fosters wider collaboration and increased citations

- maximum visibility for your research: over $100 \mathrm{M}$ website views per year

At BMC, research is always in progress.

Learn more biomedcentral.com/submissions 